\title{
OPEN Fibroblast growth factor 2 accelerates the epithelial-mesenchymal transition in keratinocytes during wound healing process
}

\author{
Yuta Koike ${ }^{\bowtie}$, Mariko Yozaki, Atsushi Utani \& Hiroyuki Murota
}

In the wound healing process, the morphology of keratinocytes at the wound edge temporarily changes to a spindle morphology, which is thought to occur due to an epithelial-mesenchymal transition (EMT). Fibroblast growth factor (FGF) 2, also called basic FGF, has the potential to accelerate wound closure by activating vascular endothelial cells and fibroblasts. We examined the effects of FGF2 on keratinocyte morphology and EMT in wounded skin. Histological examination of murine wounds treated with FGF2 revealed that wound edge keratinocytes formed thickened and multilayered epithelia. In addition, we detected wound edge keratinocytes migrating individually toward the wound center. These migrating keratinocytes exhibited not only spindle morphology but also down-regulated E-cadherin and up-regulated vimentin expression, which is characteristic of EMT. In FGF2-treated wounds, a PCR array revealed the upregulation of genes related to EMT, including transforming growth factor (TGF) signaling. Further, FGF2-treated wound edge keratinocytes expressed EMT-associated transcription factors, including Snai2, and showed translocation of $\beta$-catenin from the cell membrane to the cytoplasm/nucleus. However, in vitro examination of keratinocytes revealed that FGF2 alone did not activate EMT in keratinocytes, but that FGF2 might promote EMT in combination with TGF $\beta 1$. These findings suggest that FGF2 treatment of wounds could promote keratinocyte EMT, accelerating wound closure.

The wound healing process generally consists of incorporated and overlapping stages of hemostasis, inflammation tissue formation and remodeling of injured tissue ${ }^{1,2}$. These steps involve the coordinated efforts of several cell types, including keratinocytes, fibroblasts, endothelial cells, macrophages and platelets ${ }^{3}$. Reepithelization is a phenomenon in the new tissue formation process in which keratinocytes migrate from the wound edge to the wound center on regenerated granulation tissue, driven by growth factors and cytokines released from sites of injury. In both in vitro and in vivo models, wound edge keratinocytes prepare for migration to the wound center through molecular, morphological, cytoskeletal and adhesive changes ${ }^{4-6}$. In this process, keratinocytes shift from a polarized cuboidal morphology to a more spindle morphology with an extended cytoplasm in order to migrate and close wounds rapidly, which is thought to be an epithelial-mesenchymal transition (EMT).

EMT is a biological process that allows tightly organized epithelial cells to assume a motile mesenchymal phenotype $^{7,8}$. EMT is associated with embryonic and organ development, tissue regeneration and fibrosis, cancer progression and metastasis, and wound healing process ${ }^{7,9,10}$. Although the phenomenon of EMT has not been definitively characterized, EMT is generally accepted as occurring when epithelial cells lose E-cadherin expression and gain expression of mesenchymal cell components such as vimentin and $\mathrm{N}$-cadherin ${ }^{11}$. In wound healing-associated EMT, the spatiotemporally controlled process of keratinocyte formation, in which keratinocytes can transition into a mesenchymal state and revert to an epithelial state, is proposed to be partial EMT and essential for reepithelization system ${ }^{12,13}$. EMT in the context of cancer progression is well studied, and is often compared to EMT in the context of wound healing, mainly with respect to the molecular changes and cell plasticity common to both processes ${ }^{14}$. Cancer progression-related EMT also includes a niche of intermediate states between the epithelium and mesenchyme ${ }^{15,16}$ like partial EMT on wound healing. Snai2, which belongs to the 
Snail superfamily of zinc finger transcriptional repressors, is the most investigated molecule in wound healing EMT, and is thought to be the main EMT-inducing transcription factor in cutaneous wound healing $6,12,13,17,18$.

Fibroblast growth factor (FGF) 2, also called basic FGF, is a member of a large FGF family of structurally related proteins that bind heparin sulfate and modulate the growth, differentiation, migration and survival of a wide variety of cell types ${ }^{19}$. FGF2 strongly activates not only fibroblasts but also other mesoderm-derived cells, including vascular endothelial and smooth muscle cells, osteoblasts and chondrocytes ${ }^{20}$. Administration of recombinant FGF2 to skin wounds accelerates acute and chronic wound healing ${ }^{21-23}$. Therefore, topical recombinant FGF2 has been approved in Japan for the treatment of skin ulcer since 2001. Local FGF2 administration also has an anti-fibrotic effect for the wound to antagonize myofibroblast differentiation and dampen fibrosis which has been evidenced by decreased $\mathrm{SMA}^{24}$ and fibronection in the wound tissue ${ }^{25}$. In addition, FGF2 is considered to accelerate reepithelization ${ }^{26}$, which is especially prevalent in an epidermis-defect wound model ${ }^{27}$. However, most in vitro studies have reported that FGF2 is less active in keratinocytes that are derived from primitive ectoderm, relative to mesoderm-derived cells ${ }^{28}$.

In the present study, we detected wound edge migrating and spindle keratinocytes in a mouse cutaneous wound model, which were more prevalent in FGF2-treated wounds. We tested the hypothesis that local wound FGF2 treatment would cause wound edge keratinocytes to undergo EMT, facilitating rapid migration on the wound bed to speed wound closure. Further, we characterized FGF2-induced temporal changes in keratinocytes, focusing on the molecular mechanisms of EMT.

\section{Results}

FGF2 accelerated wound healing, accompanied by individually migrating keratinocytes. To investigate the effects of FGF2 on cutaneous wound healing, $6 \mathrm{~mm}$ biopsy punch wounds were generated on the dorsal regions of C57BL/6 mice and wound healing was observed. On days 2 and 4, FGF2-treated wounds closed more rapidly than vehicle-treated wounds (Fig. 1a). The average period required for wound closure was significantly shorter in the FGF2-treated group ( $7.8 \pm 0.2$ days) than in the control group ( $9.8 \pm 0.3$ days, $p<0.01$; Fig. 1b). In addition, histological examination 4 days after wounding revealed thickening on the edge of the epidermal layer in FGF2-treated wounds (Fig. 1c). The numbers of keratinocytes layer of wound edge were increased in FGF2-treated wounds, with an average of $12.5 \pm 2.5$ keratinocytes in the FGF2-treated group and $7.0 \pm 1.5$ keratinocytes in the control group $(p<0.01$; Fig. $1 \mathrm{~d}$ ). At day 4 after induction of skin wounds, histological examination revealed that keratinocytes in FGF2-treated wounds protruded from the surface, and that spindle-shaped keratinocytes migrated from the wound edge into fibrin clots or granulation tissue (Fig. 1e). Immunofluorescence staining with an anti-pan-keratin antibody confirmed the migrating cells to be keratinocytes (Fig. 1f). The number of migrating keratinocytes was significantly higher in the FGF2-treated group $(4.3 \pm 1.2$ cells) than in the control group $(0.3 \pm 0.2$ cells, $p<0.01$; Fig. 1 g). Thus, murine FGF2-treated wounds exhibited rapid wound closure, accompanied by epithelial proliferation at the wound edge. Additionally, the characteristic spindle morphology and individual migration observed in FGF2-treated wounds suggested that wound edge keratinocytes had acquired a mesenchymal phenotype.

Immunofluorescent evaluation of EMT-related cell morphological components. To determine if the observed individually migrating cells had acquired mesenchymal cell characteristics, we immunostained FGF2-treated wounds 4 days after wounding. Cell membrane E-cadherin expression was reduced in wound edge keratinocytes both in FGF2 treated wounds and in vehicle-treated wounds. The down-regulated E-cadherin was also seen in keratinocytes detached from the wound edge in the fibrin clot (Fig. 2a). Interestingly, the wound edge and individually migrating keratinocytes in the FGF2-treated wound co-expressed the intermediate filaments cytokeratin and vimentin (Fig. 2b). Among sections of FGF2-treated wounds on day 4, we detected spindleshaped monolayer keratinocytes on the portion of granulation tissue referred to as the epithelial tongue (Fig. 2c). These migrating keratinocytes were strongly positive for vimentin and cytokeratin. In addition, cell membrane E-cadherin was nearly undetectable (Fig. 2d). The number of vimentin and cytokeratin co-expression cells in the wound edge and migrating keratinocytes were significantly higher in FGF2 treated wounds (30.2 \pm 5.3 cells) than in the control group $(5.2 \pm 2.6$ cells, $p<0.01$; Fig. $2 \mathrm{e})$. Thus, these findings suggested that wound edge and migrating keratinocytes decreased E-cadherin regardless of the FGF2 application or not. In addition, those keratinocytes observed in FGF2-treated wounds acquired typical morphological and molecular features of EMT, which were characterized by not only decreased E-cadherin but also increased vimentin.

PCR array analysis of wound tissue EMT-associated molecules. A tissue PCR array of 84 EMTassociated components (See Supplementary Data. S2 online) was performed using RNA extracted from fullthickness mouse wounds on day 4, treated with FGF2 $(n=3)$ or PBS $(n=3)$. Out of targets, 34 transcripts were at least 1.5-fold upregulated, and 11 were at least 1.5-fold down-regulated in FGF2-treated wounds compared to control wounds. Genes were categorized into five groups, including genes typically upregulated during EMT, cell growth and proliferation genes, cell migration and motility genes, genes related to TGF/bone morphogenetic protein (BMP) signaling, and genes related to Wnt signaling. Of these gene categories, the 34 upregulated genes in the in FGF-treated group included ten genes in the EMT category, nine genes in the cell growth and proliferation category, five genes in the cell migration and motility category, four genes in the TGF/BMP signaling category and three genes in the Wnt signaling category (Fig. 3). Fewer genes in each category were downregulated in the FGF2 group. To confirm the expression of major EMT-associated genes, we selected representative genes that are commonly investigated in the study of EMT from the PCR array data. Individual results from PCR array revealed changes in mRNA levels of TGF $\beta 1$ (2.79 \pm 0.34 fold: $p<0.01)$, TGF $\beta 2$ (1.18 \pm 0.34 fold), TGF 33 ( $2.34 \pm 0.45$ fold: $p<0.05), \beta$-catenin (1.70 \pm 0.32 fold), Snai1 ( $2.72 \pm 0.90$ fold), Snai2 (1.12 \pm 0.90 fold), 

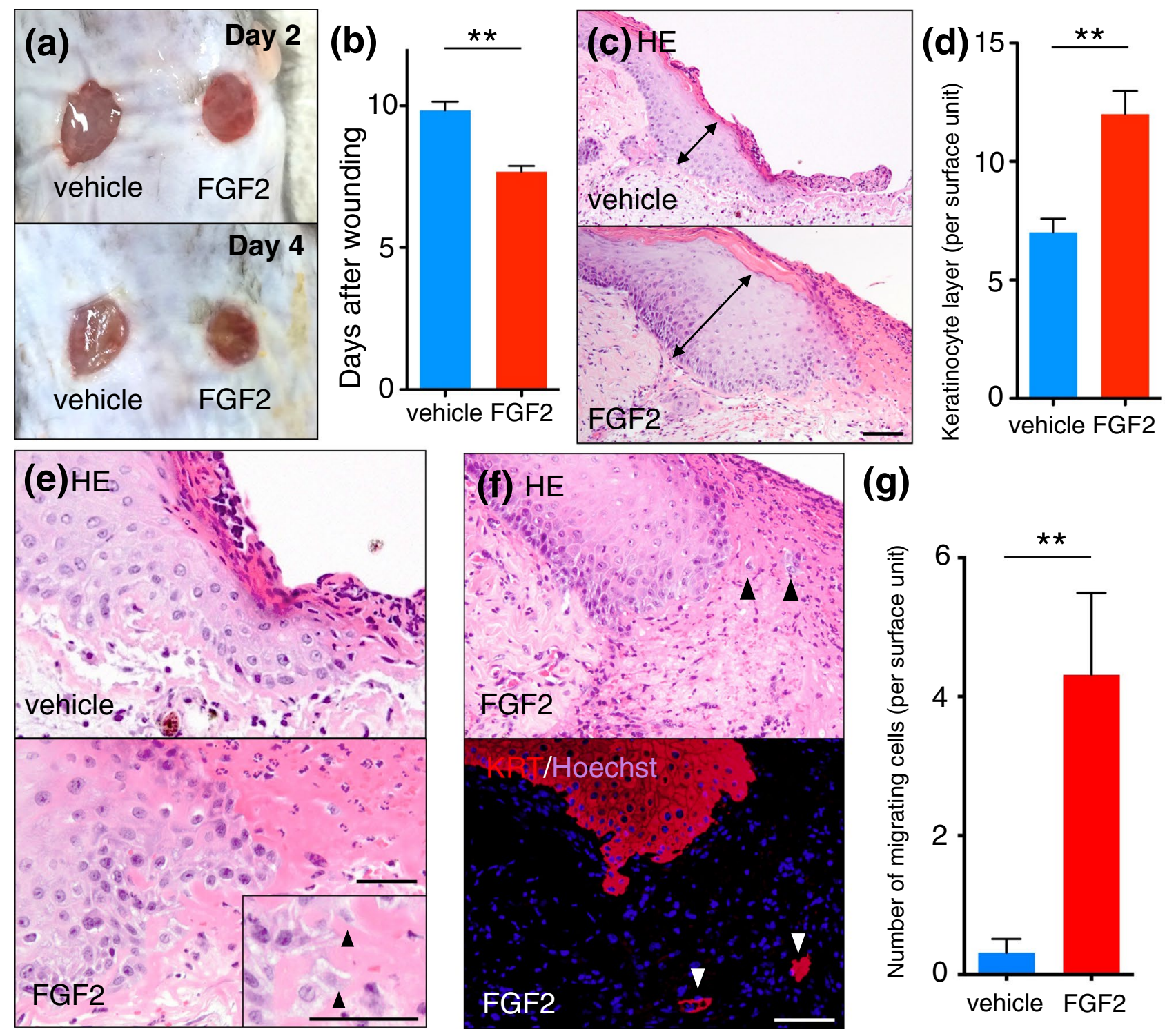

Figure 1. FGF2 accelerated wound healing, epidermal hypertrophy and keratinocytes migration at wound edge. (a) Murine wounds were created on the dorsal skin using $6 \mathrm{~mm}$ punch, and FGF2-treated wounds were significantly smaller on day 4. (b) Days required for wound closure were significantly decreased by FGF2 treatment. (c,d) FGF2-treated wounds demonstrated a more thickened epidermis (double arrow) than vehicletreated wounds. Scale bar: $40 \mu \mathrm{m}$. (e) At the wound edge, spindle-shaped keratinocytes (arrow heads) were observed in FGF2-treated wounds (higher magnification images at the corner). Scale bar: $20 \mu \mathrm{m}$. (f) Cells migrating in fibrin clots (arrow heads) were confirmed to be keratinocytes by immunofluorescent staining with anti-pan keratin antibody. Scale bar: $40 \mu \mathrm{m}$. (g) The number of migrating keratinocytes was significantly higher in FGF2-treated wounds than in control wounds. Bar graphs are presented with the mean values \pm standard error. FGF2: fibroblast growth factor 2, HE: hematoxylin and eosin staining. ${ }^{* *} p<0.01$, Mann-Whitney $U$ test.

Twist1 ( $0.76 \pm 0.34$ fold), Notch1 (7.14 \pm 1.59 fold: $p<0.01)$, Zeb1 $(0.39 \pm 0.04$ fold: $p<0.01)$, Smad2 $(1.48 \pm 0.84$ fold:) and Wnt5a (1.23 \pm 0.66 fold) in the FGF2 group relative to control (Fig. 4). Taken together, these findings suggested that EMT associated components, including transcriptional regulators and cytokines in the TGF/ BMP and Wnt signaling axes, were activated in FGF2-treated wound tissue. TGF $\beta 1$, a potent inducer of EMT, was significantly upregulated in FGF2-treated wound tissue, suggesting that TGF $\beta 1$ could be a key regulator of FGF2-mediated EMT enhancement.

Immunofluorescent staining of EMT-associated transcription factors. We performed tissue immunofluorescent staining of the non-affected epidermis (normal skin), vehicle-treated wound (control), and FGF2-treated wound at day 4 after wounding to evaluate expression and localization of EMT-associated factors at wound edge keratinocytes. As a representative result (Fig. 5), Snail was not present in normal skin, control and FGF2 treated-wound. Snai2 was robustly expressed in the nucleus of wound edge keratinocytes in the FGF2 

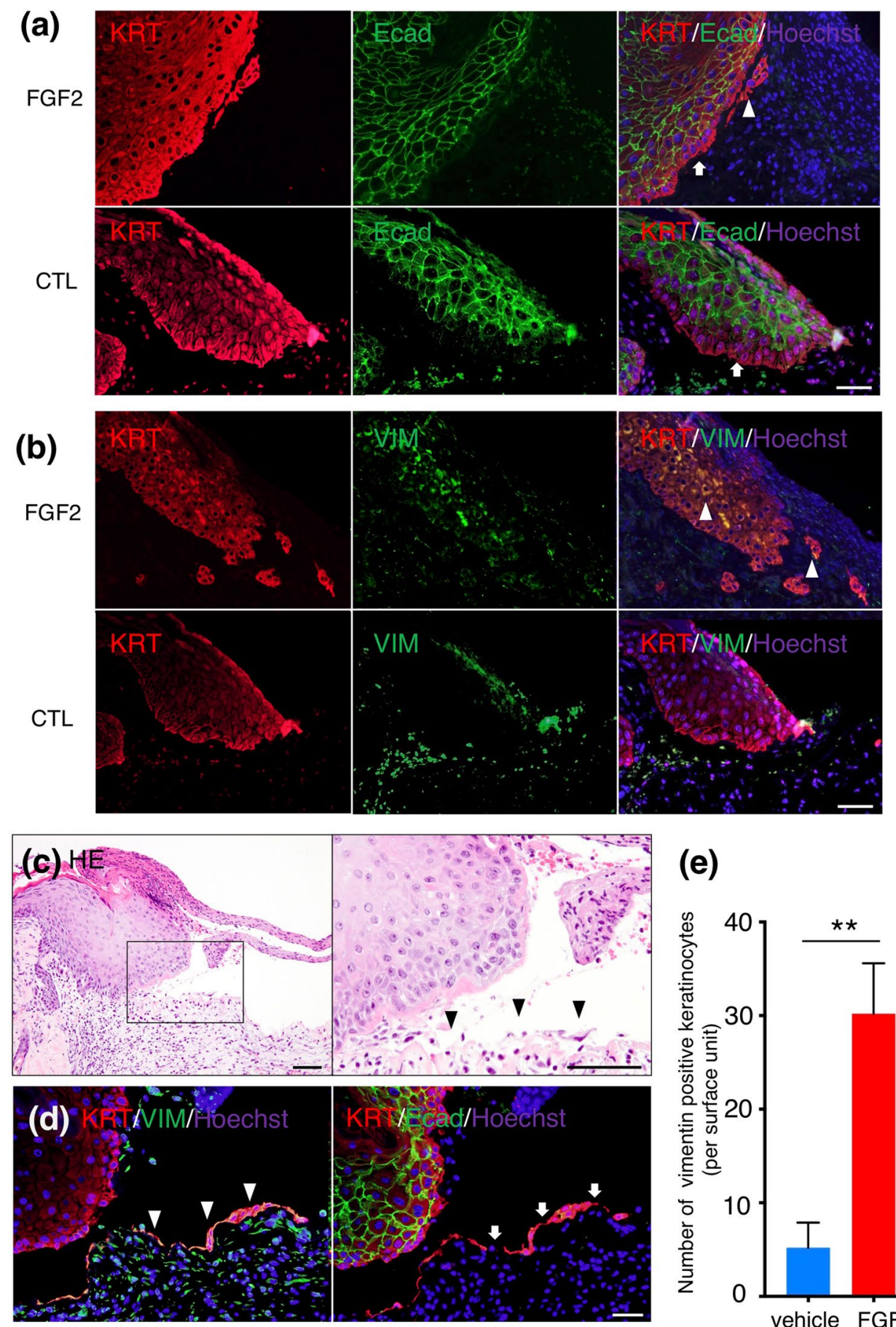

\section{(e)}

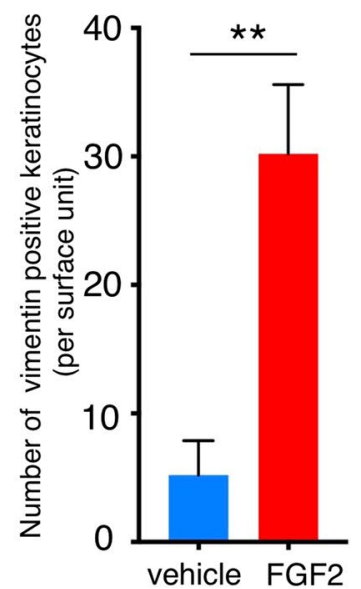

Figure 2. Immunofluorescent staining of wound edges treated with FGF2 or vehicle (control: CTL) after 4 days. (a) Cell membrane expression of E-cadherin was reduced in wound edge keratinocytes (arrows) in both FGF2 treated and CTL groups, as well as in keratinocytes away from wound edges in FGF treated group (arrowheads). Scale bar: $20 \mu \mathrm{m}$. (b) Keratinocytes at the wound edge and during migration in the fibrin clot co-expressed cytokeratin and vimentin (arrowheads) in FGF2 treated group. Scale bar: $20 \mu \mathrm{m}$. (c) Among HE sections of FGF2-treated wounds, spindle-shaped monolayer keratinocytes (arrowheads) were detected on granulation tissue Scale bar: $40 \mu \mathrm{m}$ (d) and showed were strongly positive for vimentin as well as cytokeratin (arrowheads). In addition, cell membrane E-cadherin was nearly undetectable (arrows). Scale bar: $20 \mu \mathrm{m}$ (e) The number of vimentin-positive wound edge and migrating keratinocytes at the FGF2 treated condition was significantly more than vehicle-treated wounds. Bar graph is presented with the mean values \pm standard error. KRT: pan-keratin, Ecad: E-cadherin, VIM: vimentin. ${ }^{* *} p<0.01$, Mann-Whitney $U$ test. 


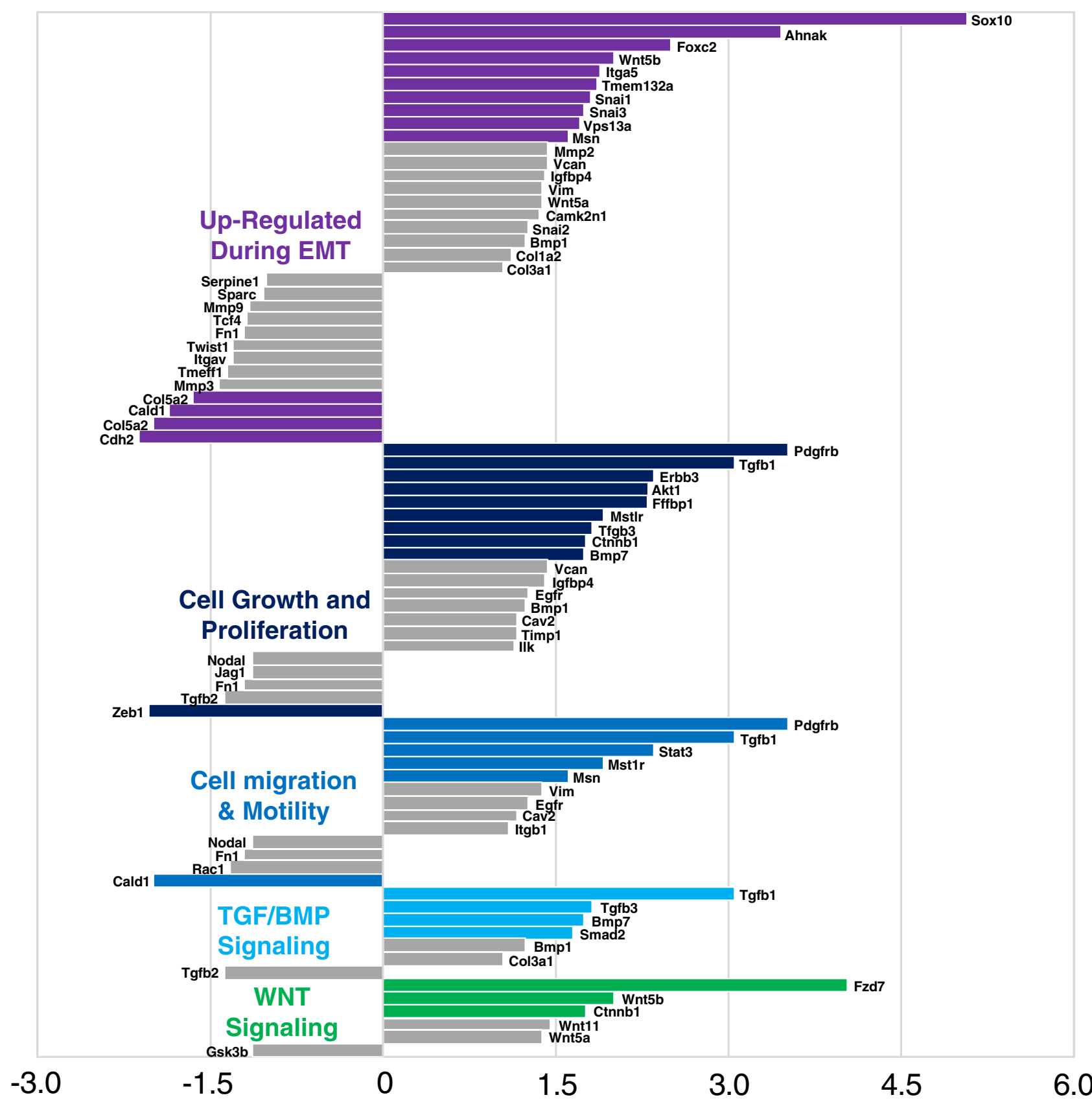

Figure 3. Tissue PCR array analysis about EMT associated components in murine wounds. Eighty-four EMT associated components were examined in RNA extracted from whole wounds at day 4 treated with vehicle or FGF2 ( $n=3$ /group). Genes were categorized into five groups, including genes typically upregulated during EMT, cell growth and proliferation genes, cell migration and motility genes, genes related to TGF/bone morphogenetic protein (BMP) signaling, and genes related to Wnt signaling. Genes indicated with colored bars were up or down-regulated $>1.5$ fold change.

group, faintly expressed in a few keratinocytes in control and not expressed in normal skin. Twist was detected in the cytoplasm of wound edge keratinocytes in the FGF2 group, but almost not detected in the normal skin and in the control group. $\beta$-catenin comprises the cell attachment structure of keratinocytes. In FGF2-treated wounds, some wound edge keratinocytes showed activation of $\beta$-catenin signaling evidenced by translocation of $\beta$-catenin from the cell membrane to the cytoplasm or nucleus, which was slightly seen in the control mock treated group. The immunofluorescent staining pattern of Notch1 did not differ among normal epidermis, control wounds and FGF2-treated wounds. Taken together, these findings suggest that keratinocyte EMT in FGF2treated wounds might be regulated by transcription factors such as Snai2, Twist and $\beta$-catenin.

In vitro assay of cultured keratinocytes treated with FGF2 and TGF $\beta 1$. In wounds treated with FGF2, we identified TGF $\beta 1$ mRNA upregulation in the whole tissue extract and upregulation of EMT-associated 


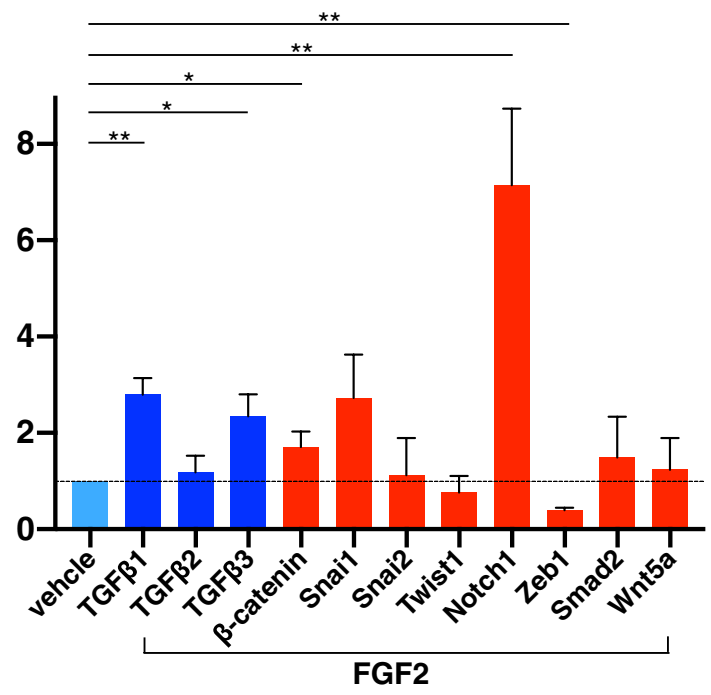

Figure 4. Representative EMT-associated upregulated genes in PCR array analysis. Individual genes of the FGF2 group were normalized by the same gene of vehicle group respectively. TGF $\beta 1$ (2.79 fold: $p<0.01)$, TGF $\beta 2$ (1.18 fold), TGF $\beta 3$ (2.34 fold: $p<0.05), \beta$-catenin (1.70 fold: $p<0.05)$ and Notch1 $(7.14$ fold: $p<0.01)$ were up-regulated and Zeb1 (0.39 fold: $p<0.01)$ was down-regulated significantly in comparison with vehicletreated samples. Bar graph is presented with the mean values \pm standard error. ${ }^{*} p<0.05,{ }^{* *} p<0.01$, MannWhitney $U$ test.

transcription factors in wound edge keratinocytes. As TGF $\beta 1$ is a major inducer of $\mathrm{EMT}^{12}$, we next used an in vitro assay, in which normal human epidermal keratinocytes (NHEKs) and a keratinocyte cell line were treated with TGF $\beta 1$ and FGF2 solo-stimulation and TGF $\beta 1$ and FGF2 co-stimulation (TGF $\beta 1$ + FGF2) to determine whether FGF2 contributed to the EMT on keratinocyte. In the experiment using NHEKs, TGF $\beta 1$ and TGF $\beta 1+$ FGF2 stimulation showed disseminated proliferation of cells that implied EMT in contrast to the cobblestone pattern of control and FGF2 treated cells $48 \mathrm{~h}$ after stimulation (Fig. 6a). mRNA expression of E-cadherin, vimentin, and Snai2 was highly and significantly upregulated in TGF $\beta 1$ and TGF $\beta 1 / F G F 2$. Whereas treatment of cells with FGF2 alone did not alter the expression of E-cadherin, vimentin, and Snai2. TGF $\beta 1$ alone significantly upregulates the mRNA of these genes, however, co-treatment of keratinocytes with TGF $\beta 1$ and FGF2 further enhances the expression of only E-cadherin (Fig. 6b). A keratinocyte cell line, HaCaT cells, gradually showed not only disseminated pattern but also spindle morphology with TGF $\beta 1$ and TGF $\beta 1+$ FGF2 treatment in the time course of cell culture (Fig. 7a). In contrast, morphology was unaffected with FGF2 alone. mRNA expression of E-cadherin, vimentin and Snai2 was highly and significantly upregulated in TGF $\beta 1$. Vimentin and Snai 2 were further upregulated by TGF $\beta 1+$ FGF2 co-treatment than TGF $\beta 1$ solo treatment especially at the time point of $72 \mathrm{~h}$ (Fig. 7b). As these results using HaCaT cells revealed EMT with TGF $\beta 1$ and might imply enhancement of the TGF $\beta 1$-induced EMT with FGF2, we examined the mRNA expression of other EMT associated molecules (Fig. 7c). Snail increased with TGF $\beta 1$ but suppressed with FGF2 and TGF $\beta 1+$ FGF2 at 72 h. Twist1 was increased with TGF $\beta 1$ at 48 and $72 \mathrm{~h}$, and TGF $\beta 1+$ FGF2 at $48 \mathrm{~h}$. $\beta$-catenin was similarly upregulated by TGF $\beta 1$ and TGF $\beta 1+$ FGF2 treatment at both time points. Among EMT-inducing transcription factors, Notch1 was significantly suppressed by TGF $\beta 1$ treatment and TGF $\beta 1$ + FGF2 co-treatment. Treatment with FGF2 alone had little effect on the expression of EMT-related transcription factors in NHEK and HaCaT cells. However, when we see the expression levels of vimentin and Snai2 in TGF $\beta 1$-stimulated HaCaT cells with or without FGF2, FGF2 might affect the synergistic effect of these genes under TGF $\beta 1$ stimulation. To resolve the mechanism, we measured mRNA of FGFR1 which was one of the FGF2 receptors. As a result, FGFR1 showed a significant increase with TGF $\beta 1$ in comparison with control and FGF2 at $48 \mathrm{~h}$ in HaCaT cells (Fig. 7d). Taken together, NHEKs and $\mathrm{HaCaT}$ cells treated with TGF $\beta 1$ showed EMT but not with FGF2 alone. In HaCaT cells, some EMT markers like vimentin and Snai 2 were further upregulated by TGF $\beta 1$ + FGF2 co-treatment relative to TGF $\beta 1$ treatment alone, suggesting that FGF2 might enhance TGF $\beta 1$-mediated EMT in keratinocytes via agonizing TGF $\beta 1$-upregulated receptors like FGFR1 by expression of FGF2 recognizable receptors such as FGFR1 by TGF $\beta 1$.

\section{Discussion}

We investigated the FGF2 function in the wound healing process, focusing specifically on keratinocytes. As reported in several papers before ${ }^{21,23,26,27,29}$, FGF2 treated wound closed faster than vehicle-treated wounds. In the epidermis of wound edge, in addition to epidermal hypertrophy, spindle-shaped and migrating keratinocytes were observed. These characteristic cells revealed to express intermediate filaments, not only cytokeratin but also vimentin which usually express in mesenchymal cells and to reduce their expression of E-cadherin, suggesting an EMT. In order to evaluate the tissue molecular condition in the FGF2 treated wound, we performed a PCR array using the wound tissue which showed that the tissue environment tended to initiate EMT as well as 


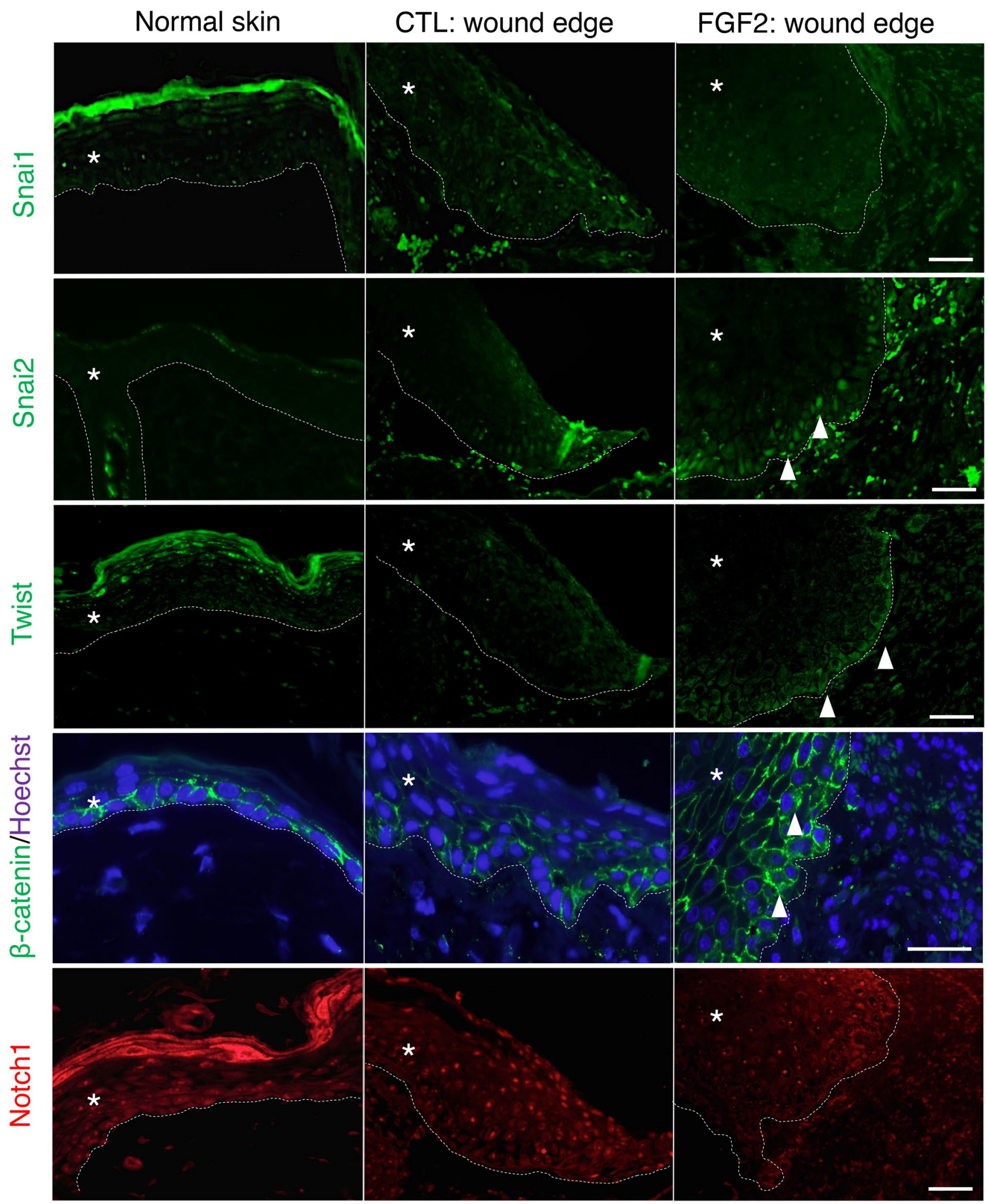

Figure 5. Immunofluorescent staining for EMT associated transcriptional factors was performed on noninjured skin (normal skin) and wound edges treated with vehicle (CTL) and FGF2 4 days after wounding. Snai1 was absent in all normal skin, CTL wounds, and FGF2-treated wounds. Snai2 was robustly expressed in wound edge keratinocytes in FGF2-treated wounds (arrowheads) and faintly expressed in those in control wounds. Twist was expressed in FGF2-treated wounds (arrowheads). $\beta$-catenin translocated from the cell membrane to the cytoplasm or nuclei (arrowheads) in the wound tissues, especially in the FGF2-treated group. Notch1 did not differ among samples. Scale bar: $40 \mu \mathrm{m}$, ${ }^{*}$ shows epidermis. 
(a)

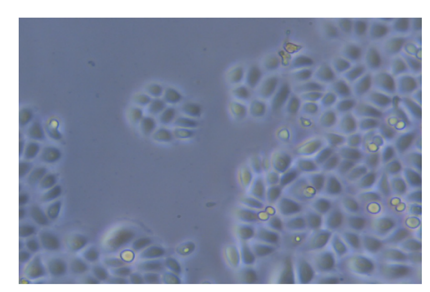

TGF $\beta 1$

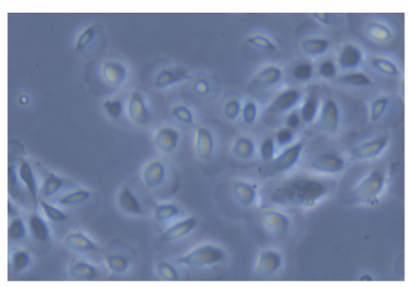

FGF2

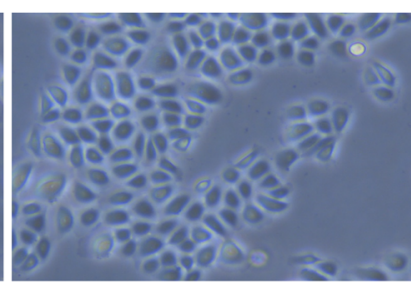

TGF $\beta+F G F 2$

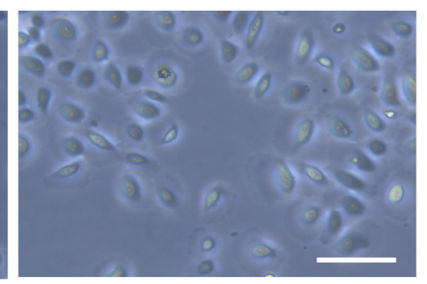

(b)

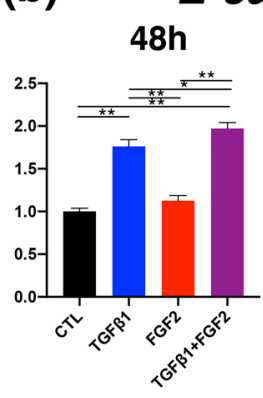

E-cadherin

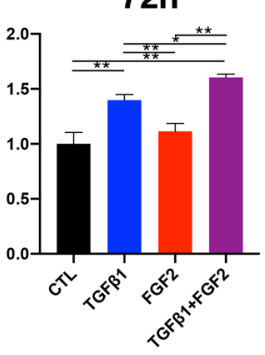

Vimentin

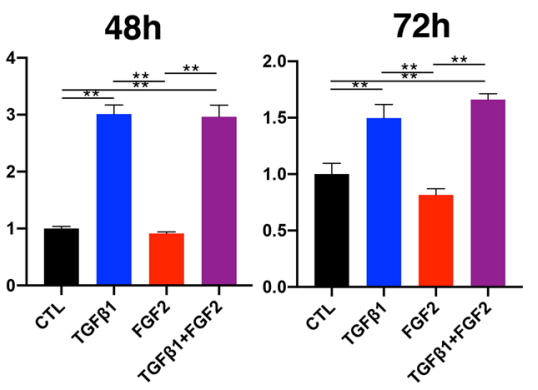

Snai2

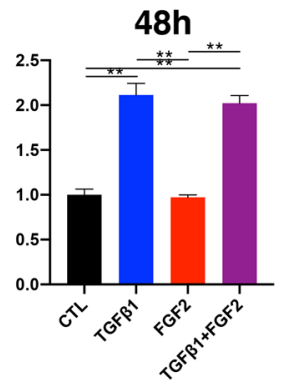

72h

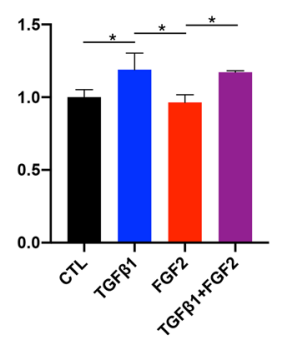

Figure 6. In vitro experiment using normal human epidermal keratinocytes (NHEKs) to compare among normal culture condition (CTL), TGF $\beta 1$ solo-stimulation, FGF2 solo-stimulation, and TGF $\beta 1$ and FGF2 co-stimulation (TGF $\beta 1+$ FGF2). (a) After 48 h of stimulation, NHEKs with TGF $\beta 1$ and TGF $\beta 1+$ FGF2 showed disseminated proliferation in contrast to the cobblestone pattern of those with normal medium and FGF2 treated condition. Scale bar: $20 \mu \mathrm{m}(\mathbf{b})$ realtime RT-PCR analysis of NHEKs. The Y-axis represents the relative ratio normalized by CTL. mRNA expressions of E-cadherin, vimentin, and Snai2 at 48 and $72 \mathrm{~h}$ stimulation were highly and significantly upregulated in TGF $\beta 1$ and TGF $\beta 1 / F G F 2$. Solo treatment with FGF2 affected little in expressions of EMT-related transcription factors in NHEKs. Bar graphs are presented with the mean values \pm standard error. ${ }^{*} p<0.05,{ }^{* *} p<0.01$, ANOVA with a post hoc Tukey examination.

cell growth, proliferation, cell migration and motility, and accelerate TGF/BMP signaling and WNT signaling. EMT associated transcriptional factors such as Snai2, Twist and $\beta$-catenin were also expressed in the wound edge keratinocytes. In in vitro examination, FGF2 treatment showed no influence on NHEKs and HaCaT cells, but FGF2 might have additional EMT effects to cells when co-stimulating with TGF $\beta$.

In partial epidermal EMT during wound healing, the cell-cell adhesion of keratinocytes is characterized by diminished desmosome components and adherens junction components, such as E-cadherin ${ }^{5,6,30,31}$. In contrast to carcinomas, upregulation of vimentin in wound healing-related EMT is still unclear ${ }^{13}$. Only one report demonstrated vimentin expression in migrating epithelial tongues of acute wounds and hypertrophic scars ${ }^{32}$. The present study identified vimentin expression in FGF2-treated wounds, especially in keratinocytes observed on the epithelial tongue, indicating that vimentin expression in keratinocytes during wound healing EMT could require specific conditions, such as tissue activation with FGF2. A study has revealed that vimentin-deficient wounds exhibited loss of EMT-like keratinocyte activation, limited keratinization and slow reepithelization ${ }^{33}$, demonstrating the importance of vimentin-positive keratinocytes in the reepithelization process.

Among EMT-associated transcription factors, several reports support the functional involvement of Snai2 in cutaneous wound healing ${ }^{6,17,18}$. In the present study, Snai2 expression was clearly observed in wound edge keratinocytes treated with FGF2 in vivo. Additionally, TGF $\beta 1$ induced Snai2 mRNA expression by which was significantly upregulated by co-treatment with FGF2 in HaCaT cells. A prior study identified that Snai2-null mice presented non-healing cutaneous ulcers in response to ultraviolet radiation ${ }^{6,34,35}$. Upregulation of Snai2 in the nuclei of keratinocytes at the edges of FGF2-treated wounds ${ }^{36,37}$ supported the importance of Snai2 in keratinocyte migration and tissue regeneration. Other EMT-associated transcription factors such as Twist ${ }^{38}$ and $\beta$-catenin ${ }^{36,37}$ have been reported to express in keratinocytes at wound-healing process, as well as in tumor cells as hallmarks of $\mathrm{EMT}^{14}$.

The Snail family, including Snail and Snai2, regulates EMT associated gene transcription downstream of TGF signaling ${ }^{18,39}$. FGF2-treated wounds exhibited 3.05-fold upregulation of TGF $\beta 1$ in comparison to vehicletreated wounds. This result indicated that TGF $\beta 1$ could have provoked EMT as a messenger of FGF2 in the wound tissue. Translocation of $\beta$-catenin from the cell membrane to the cytoplasm or nucleus was observed in the wound edge keratinocytes of wounds treated with FGF2. E-cadherin not only connects keratinocyte membranes, but also sequesters $\beta$-catenin to the cell membrane to suppress Wnt- $\beta$-catenin signaling, which regulates key migration events of $\mathrm{EMT}^{40}$. In keratinocytes, this phenomenon is thought to participate in the wound healing process ${ }^{41}$. Notch signaling has various functions, including epidermal differentiation ${ }^{41}$ and EMT $^{11}$. Our PCR array results revealed greater expression of Notch1 mRNA in FGF2-treated wound tissue than in control 
wound tissue, however Notch1 was only marginally induced in wound edge keratinocytes in either group and also down-regulated in in vitro HaCaT model treated with TGF $\beta 1$ and TGF $\beta 1+$ FGF2. Notch1 is essential for epidermal proliferation and differentiation ${ }^{42}$. A recent study revealed that Notch 1 expression is down-regulated in epidermal keratinocytes at the regeneration phase in the wound healing process ${ }^{43}$. From these facts, Notch 1 would contribute to suppress epidermal differentiation but not influence the EMT in wound edge keratinocytes even when stimulating with topical FGF2. The significant up-regulation of Notch1 at the PCR array data in FGF2 treated wound tissue might be due to overall activation of cells especially in the regenerated dermis. Taken together, our results suggest that when FGF2 is applied to wounds during the acute phase, increased TGF $\beta 1$ may stimulate EMT signaling in wound edge keratinocytes, upregulating EMT-associated transcription factors such as Snai2. Finally, EMT, which is characterized by diminished E-cadherin and expression of vimentin, could occur, supporting wound healing.

Although FGF2 accelerates reepithelization in the wound healing process ${ }^{26,27}$, the direct effects of FGF2 on epidermal keratinocytes remain controversial. A small number of studies have suggested that direct FGF2 stimulation activates keratinocytes. In vitro studies using NHEKs demonstrated that FGF2 could stimulate keratinocyte proliferation $^{44}$. Nakamizo et al. demonstrated FGF2 promoted NHEKs proliferation, which was inversely dependent on cell density, as cells in high-density culture exhibited decreased FGF receptor expression ${ }^{45}$. In the present study, we demonstrated that FGF2 treatment alone had little impact on EMT and cell morphology in NHEKs and HaCaT cells. Intriguingly, our results on HaCaT cells also suggested that TGF $\beta 1 / F G F 2$ co-treatment upregulated EMT-associated genes more robustly than TGF $\beta 1$ treatment alone. Shirakihara et al. suggested that TGF $\beta$ and FGF2 cooperatively initiate EMT using NMuMG cells, a mouse mammary epithelial cell line. When NMuMG cells were co-stimulated with TGF $\beta$ and FGF2, TGF $\beta$ regulated isoform switching of FGF receptors from FGFR2IIIb into a FGF2-recognizable FGF receptor, FGFR1IIIc. Consequently, FGF2 co-treatment increased the migratory capacity of NMuMG cells, and induced morphological changes consistent with EMT relative to TGF $\beta$ treatment alone ${ }^{46}$. Our HaCaT model also might suggest a similar mechanism, by which TGF $\beta$ might initiate FGF receptor isoform switching into FGFR1 to allow FGF2 recognition, further promoting EMT.

In the present study, several limitations exist. In the in vivo wound healing model mainly documented in Fig. 1, additional factors modulating the acceleration of wound healing should be considered. Skin contraction resulting in faster healing, with temporarily increased myofibroblast is the main player ${ }^{47}$. TGF $\beta$ is known to increase differentiation of fibroblasts into myofibroblasts ${ }^{48,49}$, and thus, local administration of FGF2 which induce TGF $\beta$ mRNA in the tissue may indirectly reduce time to healing. On the other hand, local administration of FGF2 is also reported to suppress differentiation of fibroblasts to myofibroblasts in vivo ${ }^{50,51}$. Taken together, topical administration of FGF2 was revealed to shorten the period of wound healing despite suppression of myofibroblast differentiation. The mechanism responsible for FGF2 accelerating wound healing without skin contraction can be speculated to include neovascularization, modulated collagen and matrix deposition, as well as keratinocyte EMT. Various cell types may participate in these processes, but the current study focused on wound edge keratinocytes, representing a difficult-to-quantify site, both in morphology and molecular expression.

In summary, the results obtained in the present study suggest that topical application of FGF2 on cutaneous wound upregulates tissue mRNA of TGF $\beta 1$ and other EMT associated molecules, accelerates EMT of wound edge keratinocytes, and might contribute to reepithelization during new tissue formation.

\section{Materials and methods}

Mouse wound healing experiment. All experiments were approved by the committee for Animal Experimentation of Nagasaki University Graduate School of Biomedical Sciences (approval number 1710261420). All methods were carried out in accordance with relevant guidelines and regulations. Male C57BL6/J mice, 8-12 weeks old, were used for experiments and analysis. The dorsal skin was shaved and and two full thickness excisional wounds were created with a $6 \mathrm{~mm}$ sterile biopsy punch on the left and right dorsal skin. Recombinant FGF2 (trafermin; Kaken, Japan) diluted to $100 \mu \mathrm{g} / \mathrm{ml}$ (approved concentration for skin ulcer on human ${ }^{29}$ ) with phosphate buffered saline (PBS) was prepared. The FGF2 solution $(50 \mu \mathrm{l})$ was dropped on the right wounds, and PBS $(50 \mu \mathrm{l})$ was dropped on the left wounds as a control, and then covered with film dressing. For the following days, daily treatment with $50 \mu \mathrm{l}$ PBS or FGF2 solution and dressing changes were performed. The day of macroscopic wound closure was defined as the first day with no exudate fluid and no scab ( $\mathrm{n}=6$, respectively).

Histology. Skin samples day 4 after wounding were obtained from seven murine and fixed in formalin and paraffin-embedded. Sections were stained with hematoxylin and eosin staining. Morphologic characteristics of wound samples were assessed by light microscopy. We chose one section whose both sides of epidermal edges had been clearly found from individual samples and counted numbers of cell layers at the most thickened site and migrating keratinocytes of the bilateral epidermis wound edge $(n=14$, individually).

Immunofluorescence analysis. For immunofluorescence analysis of paraffin sections, four samples were deparaffinized and antigens were retrieved with autoclave $121^{\circ} \mathrm{C} 3 \mathrm{~min}$, in $10 \mathrm{mM}$ Sodium Citrate Buffer (pH6.0). After washing, samples were blocked with 10\% fetal bovine serum (FBS)/PBS at room temperature for 30 min. Primary antibodies (See Supplementary Data. S1 online) were used at 1:50-200 dilutions in 10\%FBS/ PBS and incubated overnight at $4{ }^{\circ} \mathrm{C}$. After washing, secondary antibodies (goat anti-mouse or rabbit IgG $(\mathrm{H}+\mathrm{L})$, Alexa Fluor 488-, 546- or 594-conjugated; Thermo Fisher Scientific Inc. US), 1:100 diluted in 10\% FBS/ PBS, were used with or without Hoechst 33342 (Invitrogen, USA) for nuclear staining at $37^{\circ} \mathrm{C}$ for $30 \mathrm{~min}$. After washing and mounting, sections were observed with a fluorescence microscope. For the detection of vimentinpositive keratinocytes, we chose one section whose both sides of epidermal edges had been clearly found from 
(a)

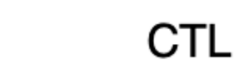

TGF $\beta 1$

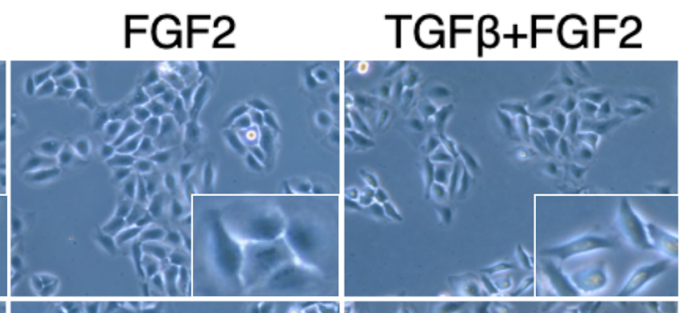

$48 \mathrm{~h}$
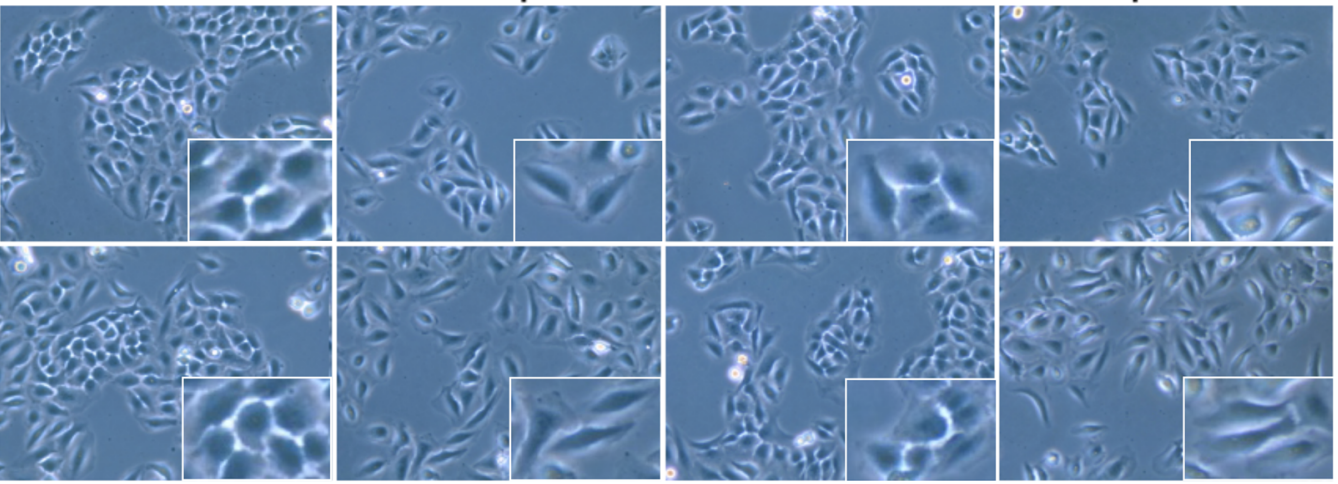

$72 \mathrm{~h}$
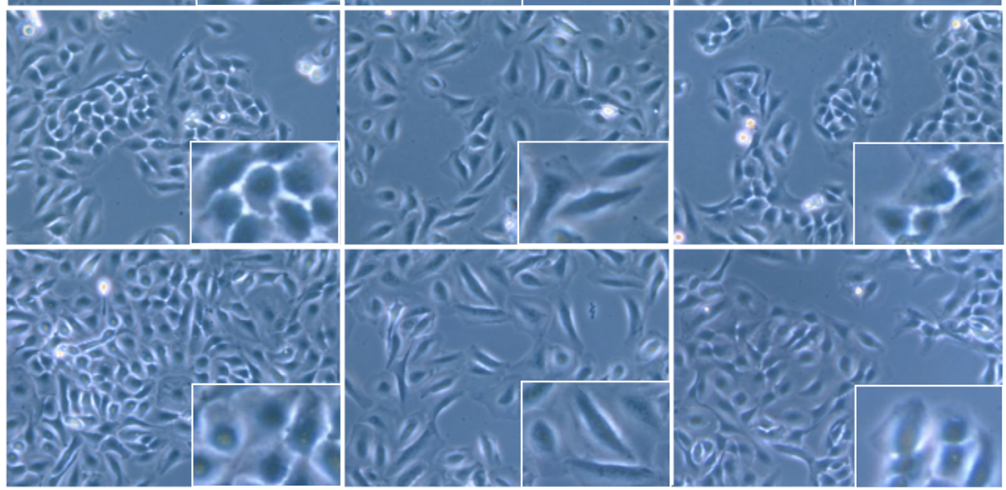

(b)

E-cadherin $48 \mathrm{~h}$
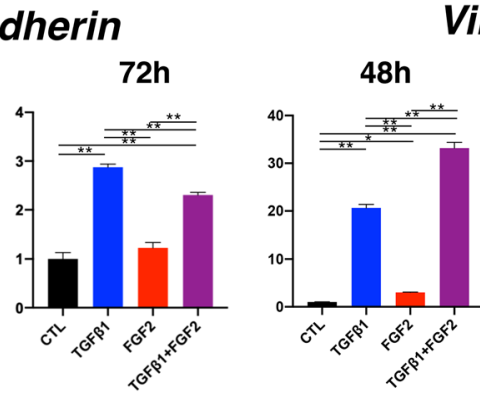

Vimentin

Snai2
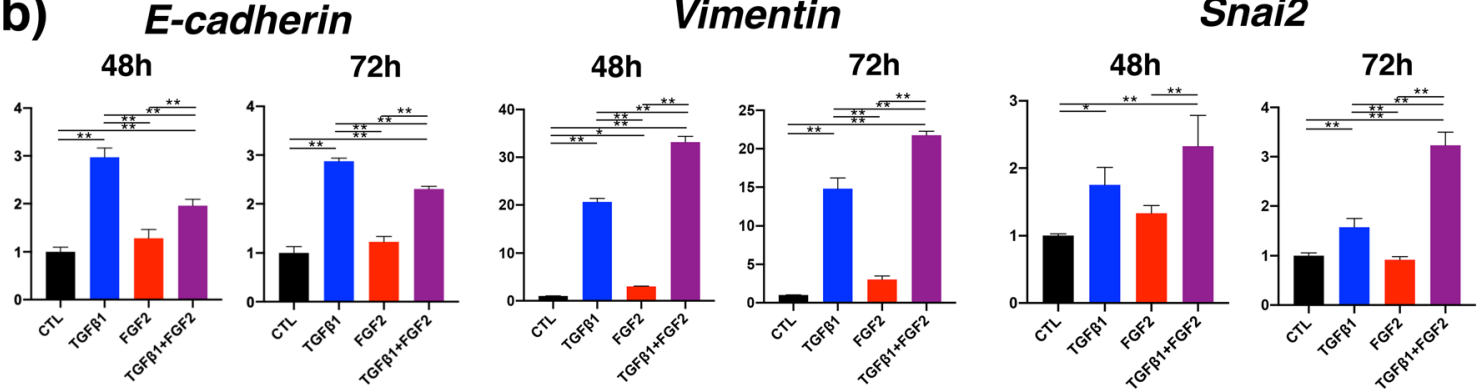

(c)

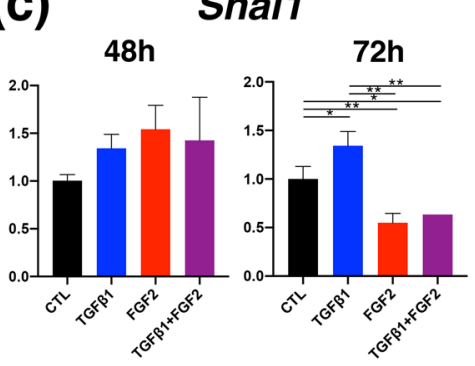

\section{$\beta$-catenin}

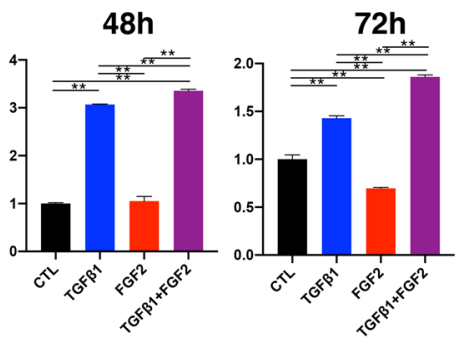

Twist1

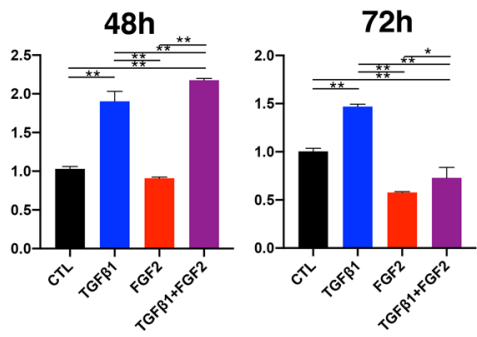

Notch1

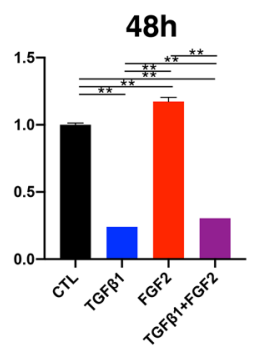

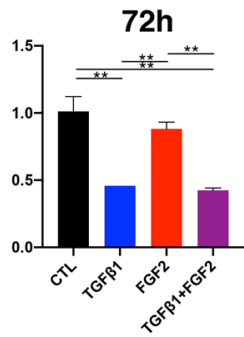

(d)

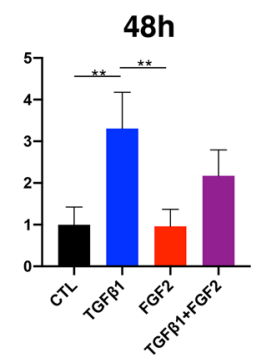

FGFR1
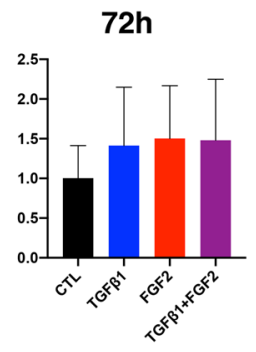

three individual samples and counted numbers of vimentin-positive keratinocytes from the bilateral epidermis wound edge ( $n=6$, individually).

Tissue PCR array. Around the biopsy punch wounds, a $10 \mathrm{~mm}$ square of full-thickness tissues of FGF2 treated wounds and vehicle-treated wounds were removed $(n=3$, respectively). Tissue samples from mouse wounds were immediately treated with RNAlater (Qiagen, Germany). Total tissue RNA was subsequently 
४Figure 7. In vitro experiment using $\mathrm{HaCaT}$ cells to compare among normal culture condition, TGF $\beta 1$ solo-stimulation, FGF2 solo-stimulation, and TGF $\beta 1$ and FGF2 co-stimulation (TGF $\beta 1+$ FGF2). (a) HaCaT cells gradually showed not only the disseminated pattern but also spindle morphology with TGF $\beta 1$ and TGF $\beta 1+$ FGF2 treatment in the time course of cell culture from 24 to $72 \mathrm{~h}$. Higher magnification images are at the corners. Scale bar: $20 \mu \mathrm{m}$ (b) Realtime RT-PCR analysis of HaCaT cells. The Y-axis represents the relative ratio compared with CTL. mRNA expression of E-cadherin, vimentin and Snai2 was highly and significantly upregulated in TGF $\beta 1$. Vimentin and Snai2 were further upregulated by TGF $\beta 1+$ FGF2 co-treatment than TGF $\beta 1$ solo treatment especially at the time point of 72 h. (c) mRNA expression of Snail increased with TGF $\beta 1$ but suppressed with FGF2 and TGF $\beta 1+$ FGF2 at $72 \mathrm{~h}$. Twist 1 was increased with TGF $\beta 1$ at 48 and $72 \mathrm{~h}$, and TGF $\beta 1+$ FGF 2 at 48 h. $\beta$-catenin was similarly upregulated by TGF $\beta 1$ and TGF $\beta 1+$ FGF2 treatment at both time points. Notch1 was significantly suppressed by TGF $\beta 1$ and TGF $\beta 1+$ FGF2 treatment. Solo treatment with FGF2 affected little in expressions of EMT-related transcription factors in HaCaT cells. (d) Transcription of FGFR1 in HaCaT cells showed a significant increase with TGF $\beta 1$ in comparison with control and FGF2 treatment at $48 \mathrm{~h}$. Bar graphs are presented with the mean values \pm standard error. ${ }^{\star} p<0.05,{ }^{* *} p<0.01$, ANOVA with a post hoc Tukey examination.

treated with DNase I (Qiagen) and further purified using a RNeasy Mini Kit (Qiagen). A total of $1 \mu \mathrm{g}$ of RNA was purified as per the manufacturer's protocol then reverse transcribed using a First Strand Synthesis Kit (Qiagen) per manufacturer's instructions, and subsequently loaded onto an EMT-associated molecule RT ${ }^{2}$ profiler array according to the manufacturer's instructions (Qiagen). Fold change was calculated by determining the ratio of mRNA level to control values using the $\Delta$ threshold cycle $(\mathrm{Ct})$ method $\left(2^{-\Delta \Delta \mathrm{Ct}}\right)$.

Cell culture. NHEKs were obtained from Lonza (Basel, Switzerland) and cultured in keratinocyte growth medium supplemented with bovine pituitary extract, recombinant epidermal growth factor, insulin, hydrocortisone, transferrin, and epinephrine (KGM-Gold Keratinocyte Growth Medium BulletKit, Lonza) and grown in a humidified $5 \% \mathrm{CO} 2$ atmosphere at $37^{\circ} \mathrm{C}$. For experiments, $0.1 \times 10^{6}$ cells/well (6-well plate) were seeded and grown in the above culture conditions for $24 \mathrm{~h}$ to allow cell attachment. Human immortalized keratinocytes (HaCaT cells) were maintained in Dulbecco's modified eagle medium (Nissui, Japan) supplemented with $10 \%$ fetal bovine serum, 50 units/ml penicillin $\mathrm{G}$ and $50 \mathrm{ug} / \mathrm{ml}$ streptomycin and grown in a humidified $5 \% \mathrm{CO} 2$ atmosphere at $37^{\circ} \mathrm{C}$. For experiments, $0.3 \times 10^{6}$ cells/well (6-well plate) were seeded and grown in the above culture conditions for $24 \mathrm{~h}$ to allow cell attachment, after which the cells were serum-starved for another $24 \mathrm{~h}$. The NHEKs and HaCaT cells were then cultured in the absence or presence of recombinant transforming growth factor (TGF) $\beta 1$ (2 ng/ml; R\&D systems, USA) and recombinant FGF2 (30 ng/ml). Concentrations of recombinant cytokines were determined by referring to previous experiments about FGF2 $2^{46,52}$ and TGF $\beta 1^{53,54}$.

Real-time reverse transcription PCR. Total HaCaT cell RNA was isolated using a RNeasy kit (Qiagen). Total RNA from each sample was reverse-transcribed into cDNA and analyzed with primers (See Supplementary Data. S1 online) and an ABI Prism 7000 sequence detector (Applied Biosystems, US) using a real-time PCR quantification method according to the manufacturer's instructions and description in the past report ${ }^{55}$. Sequence-specific primers and probes were designed by pre-developed TaqMan assay reagents or Assay-OnDemand (Applied Biosystems). Relative expression of real-time PCR products was determined using the $\Delta \Delta C_{\mathrm{T}}$ method to compare target gene and GAPDH mRNA expression.

Statistical analyses. The results are given as means \pm standard error of the mean. Statistical analyses were performed using GraphPad Prism 8 (GraphPad, San Diego, CA, USA). When two groups were analyzed, the data were performed using Mann-Whitney $U$ test. When three or more groups were analyzed, the data were analyzed by ANOVA with a post hoc Tukey examination. $p<0.05$ was considered statistically significant.

Received: 10 December 2019; Accepted: 14 October 2020

Published online: 29 October 2020

\section{References}

1. Singer, A. J. \& Clark, R. A. Cutaneous wound healing. N. Engl. J. Med. 341, 738-746. https://doi.org/10.1056/NEJM19990902341 1006 (1999).

2. Gurtner, G. C., Werner, S., Barrandon, Y. \& Longaker, M. T. Wound repair and regeneration. Nature 453, 314-321. https://doi. org/10.1038/nature07039 (2008).

3. Martin, P. Wound healing-aiming for perfect skin regeneration. Science 276, 75-81 (1997).

4. Grinnell, F. Wound repair, keratinocyte activation and integrin modulation. J. Cell Sci. 101(Pt 1), 1-5 (1992).

5. Coulombe, P. A. Towards a molecular definition of keratinocyte activation after acute injury to stratified epithelia. Biochem. Biophys. Res. Commun. 236, 231-238. https://doi.org/10.1006/bbrc.1997.6945 (1997).

6. Arnoux, V., Côme, C., Kusewitt, D. F., Hudson, L. G. \& Savagner, P. Cutaneous Wound Reepithelialization: A Partial and Reversible EMT (Springer, Berlin, 2005).

7. Kalluri, R. \& Weinberg, R. A. The basics of epithelial-mesenchymal transition. J. Clin. Investig. 119, 1420-1428. https://doi. org/10.1172/JCI39104 (2009).

8. Thiery, J. P. Epithelial-mesenchymal transitions in cancer onset and progression. Bull, Acad, Natl, Med. 193, 1969-1978 (2009) (discussion 1978-1969). 
9. Thiery, J. P., Acloque, H., Huang, R. Y. \& Nieto, M. A. Epithelial-mesenchymal transitions in development and disease. Cell 139, 871-890. https://doi.org/10.1016/j.cell.2009.11.007 (2009).

10. Nakamura, M. \& Tokura, Y. Epithelial-mesenchymal transition in the skin. J. Dermatol. Sci. 61, 7-13. https://doi.org/10.1016/j. jdermsci.2010.11.015 (2011).

11. Lamouille, S., Xu, J. \& Derynck, R. Molecular mechanisms of epithelial-mesenchymal transition. Nat. Rev. Mol. Cell Biol. 15, 178-196. https://doi.org/10.1038/nrm3758 (2014).

12. Nieto, M. A., Huang, R. Y., Jackson, R. A. \& Thiery, J. P. Emt: 2016. Cell 166, 21-45. https://doi.org/10.1016/j.cell.2016.06.028 (2016).

13. Haensel, D. \& Dai, X. Epithelial-to-mesenchymal transition in cutaneous wound healing: where we are and where we are heading. Dev. Dyn. 247, 473-480. https://doi.org/10.1002/dvdy.24561 (2017).

14. Leopold, P. L., Vincent, J. \& Wang, H. A comparison of epithelial-to-mesenchymal transition and re-epithelialization. Semin. Cancer Biol. 22, 471-483. https://doi.org/10.1016/j.semcancer.2012.07.003 (2012).

15. Koike, Y., Yozaki, M., Kuwatsuka, Y. \& Utani, A. Epithelial-mesenchymal transition in Bowen's disease when arising de novo and acquiring invasive capacity. J. Dermatol. 45, 748-750. https://doi.org/10.1111/1346-8138.14290 (2018).

16. Pastushenko, I. et al. Identification of the tumour transition states occurring during EMT. Nature 556, 463-468. https://doi. org/10.1038/s41586-018-0040-3 (2018).

17. Savagner, P., Yamada, K. M. \& Thiery, J. P. The zinc-finger protein slug causes desmosome dissociation, an initial and necessary step for growth factor-induced epithelial-mesenchymal transition. J. Cell Biol. 137, 1403-1419. https://doi.org/10.1083/jcb.137.6.1403 (1997).

18. Shirley, S. H., Hudson, L. G., He, J. \& Kusewitt, D. F. The skinny on slug. Mol. Carcinog. 49, 851-861. https://doi.org/10.1002/ mc.20674 (2010)

19. Bikfalvi, A., Klein, S., Pintucci, G. \& Rifkin, D. B. Biological roles of fibroblast growth factor-2. Endocr. Rev. 18, 26-45. https://doi. org/10.1210/edrv.18.1.0292 (1997).

20. Gospodarowicz, D., Ferrara, N., Schweigerer, L. \& Neufeld, G. Structural characterization and biological functions of fibroblast growth factor. Endocr. Rev. 8, 95-114. https://doi.org/10.1210/edrv-8-2-95 (1987).

21. Fu, X. et al. Randomised placebo-controlled trial of use of topical recombinant bovine basic fibroblast growth factor for seconddegree burns. Lancet 352, 1661-1664. https://doi.org/10.1016/S0140-6736(98)01260-4 (1998).

22. Akita, S., Akino, K., Imaizumi, T. \& Hirano, A. Basic fibroblast growth factor accelerates and improves second-degree burn wound healing. Wound Repair Regener. 16, 635-641. https://doi.org/10.1111/j.1524-475X.2008.00414.x (2008).

23. Xiang, Q. et al. Preparation and characterisation of bFGF-encapsulated liposomes and evaluation of wound-healing activities in the rat. Burns 37, 886-895. https://doi.org/10.1016/j.burns.2011.01.018 (2011).

24. Ishiguro, S. et al. Basic fibroblast growth factor induces down-regulation of alpha-smooth muscle actin and reduction of myofibroblast areas in open skin wounds. Wound Repair Regener. 17, 617-625. https://doi.org/10.1111/j.1524-475X.2009.00511.x (2009).

25. Shi, H. X. et al. The anti-scar effects of basic fibroblast growth factor on the wound repair in vitro and in vivo. PLoS ONE 8, e59966. https://doi.org/10.1371/journal.pone.0059966 (2013).

26. Fourtanier, A. Y. et al. Eye-derived growth factor isolated from bovine retina and used for epidermal wound healing in vivo. J. Investig. Dermatol. 87, 76-80 (1986).

27. Hebda, P. A., Klingbeil, C. K., Abraham, J. A. \& Fiddes, J. C. Basic fibroblast growth factor stimulation of epidermal wound healing in pigs. J. Investig. Dermatol. 95, 626-631 (1990).

28. Sogabe, Y., Abe, M., Yokoyama, Y. \& Ishikawa, O. Basic fibroblast growth factor stimulates human keratinocyte motility by Rac activation. Wound Repair Regener. 14, 457-462. https://doi.org/10.1111/j.1743-6109.2006.00143.x (2006).

29. Akita, S., Akino, K., Tanaka, K., Anraku, K. \& Hirano, A. A basic fibroblast growth factor improves lower extremity wound healing with a porcine-derived skin substitute. J. Trauma 64, 809-815. https://doi.org/10.1097/TA.0b013e31802c8247 (2008).

30. Moll, I., Houdek, P., Schafer, S., Nuber, U. \& Moll, R. Diversity of desmosomal proteins in regenerating epidermis: immunohistochemical study using a human skin organ culture model. Arch. Dermatol. Res. 291, 437-446 (1999).

31. Garrod, D. R., Berika, M. Y., Bardsley, W. F., Holmes, D. \& Tabernero, L. Hyper-adhesion in desmosomes: its regulation in wound healing and possible relationship to cadherin crystal structure. J. Cell Sci. 118, 5743-5754. https://doi.org/10.1242/jcs.02700 (2005).

32. Yan, C. et al. Epithelial to mesenchymal transition in human skin wound healing is induced by tumor necrosis factor-alpha through bone morphogenic protein-2. Am. J. Pathol. 176, 2247-2258. https://doi.org/10.2353/ajpath.2010.090048 (2010).

33. Cheng, F. et al. Vimentin coordinates fibroblast proliferation and keratinocyte differentiation in wound healing via TGF-beta-Slug signaling. Proc. Natl. Acad. Sci. USA 113, E4320-4327. https://doi.org/10.1073/pnas.1519197113 (2016).

34. Savagner, P. et al. Developmental transcription factor slug is required for effective re-epithelialization by adult keratinocytes. J. Cell Physiol. 202, 858-866. https://doi.org/10.1002/jcp.20188 (2005).

35. Hudson, L. G. et al. Cutaneous wound reepithelialization is compromised in mice lacking functional Slug (Snai2). J. Dermatol. Sci. 56, 19-26. https://doi.org/10.1016/j.jdermsci.2009.06.009 (2009).

36. Cheon, S. S. et al. Beta-catenin regulates wound size and mediates the effect of TGF-beta in cutaneous healing. FASEB J. 20, 692-701. https://doi.org/10.1096/fj.05-4759com (2006).

37. Stoll, S. W., Rittie, L., Johnson, J. L. \& Elder, J. T. Heparin-binding EGF-like growth factor promotes epithelial-mesenchymal transition in human keratinocytes. J. Investig. Dermatol. 132, 2148-2157. https://doi.org/10.1038/jid.2012.78 (2012).

38. Terao, M. et al. Enhanced epithelial-mesenchymal transition-like phenotype in $\mathrm{N}$-acetylglucosaminyltransferase $\mathrm{V}$ transgenic mouse skin promotes wound healing. J. Biol. Chem. 286, 28303-28311. https://doi.org/10.1074/jbc.M111.220376 (2011).

39. Sou, P. W., Delic, N. C., Halliday, G. M. \& Lyons, J. G. Snail transcription factors in keratinocytes: enough to make your skin crawl. Int. J. Biochem. Cell Biol. 42, 1940-1944. https://doi.org/10.1016/j.biocel.2010.08.021 (2010).

40. MacDonald, B. T., Tamai, K. \& He, X. Wnt/beta-catenin signaling: components, mechanisms, and diseases. Dev. Cell 17, 9-26. https://doi.org/10.1016/j.devcel.2009.06.016 (2009).

41. Bielefeld, K. A., Amini-Nik, S. \& Alman, B. A. Cutaneous wound healing: recruiting developmental pathways for regeneration. Cell Mol. Life Sci. 70, 2059-2081. https://doi.org/10.1007/s00018-012-1152-9 (2013).

42. Moriyama, M. et al. Multiple roles of Notch signaling in the regulation of epidermal development. Dev. Cell 14, 594-604. https:// doi.org/10.1016/j.devcel.2008.01.017 (2008).

43. Takazawa, Y. et al. Notch down-regulation in regenerated epidermis contributes to enhanced expression of interleukin-36alpha and suppression of keratinocyte differentiation during wound healing. J. Dermatol. Sci. 79, 10-19. https://doi.org/10.1016/j.jderm sci.2015.04.003 (2015).

44. O’Keefe, E. J., Chiu, M. L. \& Payne, R. E. Jr. Stimulation of growth of keratinocytes by basic fibroblast growth factor. J. Investig. Dermatol. 90, 767-769 (1988).

45. Nakamizo, S. et al. Topical treatment with basic fibroblast growth factor promotes wound healing and barrier recovery induced by skin abrasion. Skin Pharmacol. Physiol. 26, 22-29. https://doi.org/10.1159/000343208 (2013).

46. Shirakihara, T. et al. TGF-beta regulates isoform switching of FGF receptors and epithelial-mesenchymal transition. EMBO J. 30 , 783-795. https://doi.org/10.1038/emboj.2010.351 (2011).

47. Baum, J. \& Duffy, H. S. Fibroblasts and myofibroblasts: what are we talking about?. J. Cardiovasc. Pharmacol. 57, 376-379. https ://doi.org/10.1097/FJC.0b013e3182116e39 (2011). 
48. Ronnov-Jessen, L. \& Petersen, O. W. Induction of alpha-smooth muscle actin by transforming growth factor-beta 1 in quiescent human breast gland fibroblasts. Implications for myofibroblast generation in breast neoplasia. Lab Investig. 68, 696-707 (1993).

49. Mattey, D. L., Dawes, P. T., Nixon, N. B. \& Slater, H. Transforming growth factor beta 1 and interleukin 4 induced alpha smooth muscle actin expression and myofibroblast-like differentiation in human synovial fibroblasts in vitro: modulation by basic fibroblast growth factor. Ann. Rheum. Dis. 56, 426-431. https://doi.org/10.1136/ard.56.7.426 (1997).

50. Akasaka, Y. et al. Basic fibroblast growth factor in an artificial dermis promotes apoptosis and inhibits expression of alpha-smooth muscle actin, leading to reduction of wound contraction. Wound Repair Regener. 15, 378-389. https://doi.org/10.1111/j.1524475X.2007.00240.x (2007).

51. Akasaka, Y., Ono, I., Yamashita, T., Jimbow, K. \& Ishii, T. Basic fibroblast growth factor promotes apoptosis and suppresses granulation tissue formation in acute incisional wounds. J. Pathol. 203, 710-720. https://doi.org/10.1002/path.1574 (2004).

52. Wu, X. et al. Identification of a novel peptide that blocks basic fibroblast growth factor-mediated cell proliferation. Oncotarget 4 , 1819-1828. https://doi.org/10.18632/oncotarget.1312 (2013).

53. Rasanen, K. \& Vaheri, A. TGF-betal causes epithelial-mesenchymal transition in HaCaT derivatives, but induces expression of COX-2 and migration only in benign, not in malignant keratinocytes. J. Dermatol. Sci. 58, 97-104. https://doi.org/10.1016/j.jderm sci.2010.03.002 (2010).

54. Wang, T. et al. TGF-beta-induced miR-21 negatively regulates the antiproliferative activity but has no effect on EMT of TGF-beta in HaCaT cells. Int. J. Biochem. Cell Biol. 44, 366-376. https://doi.org/10.1016/j.biocel.2011.11.012 (2012).

55. Wong, M. L. \& Medrano, J. F. Real-time PCR for mRNA quantitation. Biotechniques 39, 75-85. https://doi.org/10.2144/05391RV01 (2005).

\section{Acknowledgements}

This work was supported by JSPS KAKENHI Grant-Aid For Young Scientists (B) Grant Number JP16K19727 and Early-Career Scientists Grant Number JP18K16032, and grant from Alumni association of Nagasaki University School of Medicine.

\section{Author contributions}

Conceptualization: K.Y., U.A.; Data curation: K.Y., Y.M.; Formal analysis: K.Y., U.A., M.H.; Funding acquisition: K.Y., U.A., M.H.; Methodology: K.Y., Y.M., U.A., M.H.; Project administration: K.Y., U.A., M.H.; Resources: K.Y., U.A., M.H.; Validation: K.Y., U.A., M.H.; Visualization: K.Y.; Writing-original draft: K.Y.; Writing-review and editing: K.Y., M.H.

\section{Competing interests}

The authors declare no competing interests.

\section{Additional information}

Supplementary information is available for this paper at https://doi.org/10.1038/s41598-020-75584-7.

Correspondence and requests for materials should be addressed to Y.K.

Reprints and permissions information is available at www.nature.com/reprints.

Publisher's note Springer Nature remains neutral with regard to jurisdictional claims in published maps and institutional affiliations.

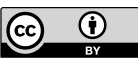

Open Access This article is licensed under a Creative Commons Attribution 4.0 International License, which permits use, sharing, adaptation, distribution and reproduction in any medium or format, as long as you give appropriate credit to the original author(s) and the source, provide a link to the Creative Commons licence, and indicate if changes were made. The images or other third party material in this article are included in the article's Creative Commons licence, unless indicated otherwise in a credit line to the material. If material is not included in the article's Creative Commons licence and your intended use is not permitted by statutory regulation or exceeds the permitted use, you will need to obtain permission directly from the copyright holder. To view a copy of this licence, visit http://creativecommons.org/licenses/by/4.0/.

(C) The Author(s) 2020 